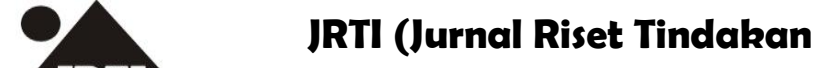 \\ -}

Volume 4 Nomor 2, Desember 2019, hlm 59-62

ISSN: 2503-1619 (Electronic)

Info Artikel:

Diterima: $12 / 10 / 2019$

Direvisi: 17/11/2019

Dipublikasikan: 31/12/2019
ISSN: 2502-079X (Print)

\section{IICET}

Indonesian institu:

Dipublikasikan oleh: Indonesian Institute for Counseling, Education and Therapy (IICET)

Akses Online :

http://jurnal.iicet.org/index.php/irtil

\title{
Kecenderungan Body Dysmorphic Disorder pada Remaja
}

\author{
Soeci Izzati Adlya ${ }^{1}$, Nilma Zola ${ }^{1}$ \\ 1 Indonesian Institute for Counseling, Education and Theraphy (IICET)
}

\begin{abstract}
Abstrak:
Kajian literatur ini bertujuan untuk mendeksripsikan tentang Body Dysmorphic Disorder (BDD) serta metode penanganannya. Setiap manusia tentu menginginkan tubuh yang sempurna, terkadang keinginan untuk mencapai kesempurnaan itu apabila telah berlebihan akan menyebabkan gangguan dismorfik tubuh atau Body Dysmorphic Disorder (BDD). Body Dysmorphic Disorder cenderung berkembang terutama pada usia remaja, apalagi seiring dengan perkembangan teknologi saat ini yang menyebabkan individu-individu saling membandingkan diri di sosial media. Body Dysmorphic Disorder adalah gangguan pikiran yang merasa adanya kecacatan dalam penampilan fisik dan menyebabkan distress dan penurunan fungsi sosial. Istilah Body Dysmorphic Disorder awalnya dikategorikan sebagai dysmorphophobia untuk menyebut perilaku tertentu yang menganggap suatu bagian tubuh tertentu pada dirinya merupakan hal yang buruk, sehingga terkadang tampak pada perilaku individu yang mengunggah foto dengan mengedit salah satu atau beberapa anggota tubuhnya. Body Dysmorphic Disorder dapat timbul karena adanya banyak faktor pendukung bukan terbentuk dari kerusakan tunggal, melainkan dari kontribusi berbagai faktor seperti biologis, psikologis, dan sosiokultural. Penderita gangguan ini dapat diberikan bantuan melalui Cognitive Behavioral Therapy.
\end{abstract}

Kata Kunci: Body dysmorphic disorder, cognitive behavioral therapy reproduction in any medium, provided the original work is properly cited. (C2019 by author

\section{PENDAHULUAN}

Manusia memiliki kecenderungan untuk mencapai kesempurnaan. Apabila hal tersebut menjadi obsesi dan tergolong pada keinginan mencapai kesempurnaan yang berlebihan terutama terkait penampilan fisik maka akan memunculkan suatu gangguan. Apalagi dengan majunya perkembangan teknologi saat ini, dimana setiap individu berlomba-lomba untuk mengaktualisasikan diri melalui social media maka hal ini akan mendorong maraknya gangguang ini. 
Body Dysmorphic Disorder (BDD) merupakan kecenderungan pikiran negatif terkait kekurangan fisik yang menyebabkan gangguan psikologis sehingga tidak dapat menjalankan kehidupan sehari-hari dengan baik. Sesuai dengan pendapat Nurlita \& Lisiswanti (2016), Body Dysmorphic Disorder (BDD) adalah preokupasi mengenai kerusakan atau kecacatan dalam penampilan fisik dan menyebabkan distress dan penurunan fungsi sosial. Body dysmorphic disorder (BDD) diartikan sebagai perasaan tidak puas yang berlebihan terhadap kondisi tubuh, pemikiran negatif dan irasional mengenai keadaan tubuh (Edmawati, Hambali \& Hidayah, 2018). Hal ini muncul diakibatkan karena nilai-nilai yang yang ada pada masyarakat serta media massa termasuk sosial media yang sangat mempengaruhi kehidupan manusia saat ini.

Pasien dengan BDD memiliki kecenderungan menjadi pasien rumah sakit jiwa (48\%), pengangguran (31\%), hingga kejadian bunuh diri (22-24\%), hal tersebut dapat terjadi akibat sikap pasien yang mengisolasi diri dari kehidupan sosial dan memiliki kesulitan dalam menjalin hubungan antar individu (Nurlita \& Lisiswanti, 2016). Penderita gangguan ini memiliki citra tubuh yang negatif atau tidak baik seperti pada bagian hidung, telinga, wajah, rambut atau fitur yang berhubungan dengan seksualitas.

Untuk lebih memahami gangguan ini, selanjutnya akan dibahas lebih lanjut tentang Body Dysmorphic Disorder ini diantaranya yaitu penyebab-penyebabnya, tanda-tanda gangguannya, dan berbagai pendekatan beserta pihak terkait untuk penanganannya.

\section{DAMPAK BODY DYSMORPHIC DISORDER}

Menurut Nurlita \& Lisiswanti (2016), individu dengan BDD diyakini menggunakan proses kognitif maladaptif yang terlalu menekankan pentingnya daya tarik yang dirasakan. Dengan pemikiran tersebut ia merasa bahwa fisiknya tidak proporsional sehingga ia memandang dirinya negatif, akibatnya mereka mengalami rendah diri, kecemasan, malu, dan kesedihan, sering melakukan metode koping maladaptif seperti memandangi cermin atau penghindaran terhadap hal yang membuat mereka sadar akan kekurangan fisik.

Kesulitan menerima kondisi diri tersebut mengakibatkan remaja memiliki self image dan citra tubuh yang negatif sehingga remaja tidak mencintai dirinya sendiri. ia merasakan ketidakpuasan terhadap dirinya sehingga menghambat tervapainya tugas perkembangannya.

Individu yang memiliki karakteristik BDD mengalami proses berpikir yang maladaptif terhadap keadaan diri. Dampak body dysmorphic disorder (BDD) dapat menjadi masalah bagi remaja jika tidak ditangani dengan tepat. Remaja akan kesulitan menerima diri sehingga sulit merasa bahagia, kesulitan mengaktualisasi diri dan dapat mengganggu perkembangan mental yang sehat (Edmawati, Hambali \& Hidayah, 2018).

\section{TANDA-TANDA GANGGUAN BODY DYSMORPHIC DISORDER}

Gambaran klinis BDD yang tampak yaitu penderita BDD merasa terdorong untuk melakukan perilaku untuk mengonfirmasi kekurangan yang dirasakan secara berulang-ulang. Perilaku tersebut termasuk kompulsif memeriksa cermin, menghindari cermin kompulsif, kompulsif perawatan (misalnya, menyisir rambut, mencabuti rambut, atau menerapkan tata rias), dan berulang-ulang membandingkan cacat dirasakan dengan tubuh orang lain (Nurlita \& Lisiswanti, 2016).

Pasien biasanya memerlukan waktu 1 jam lebih, terkadang hingga 8 jam setiap harinya dalam berfikir maupun berperilaku mengenai kekurangan tubuh yang dirasakan. Pasien dengan edukasi yang rendah cendrung menghabiskan waktu lebih lama untuk berurusan dengan kecacatan yang dibayangkannya.

Beberapa pasien BBD terkadang memerlukan orang lain untuk menghibur dan meyakinkan pasien bahwa kekurangan yang dirasakan adalah hal yang normal bukan hal yang buruk. Pasien juga sering melakukan kunjungan ulang ke dermatologis ataupun melakukan rujukan kosmetik untuk memperbaiki kecacatan (Nurlita \& Lisiswanti, 2016). 
Individu yang mengalami gejala BDD sering merasa cemas, tidak nyaman, tidak aman, tidak percaya diri, kurang menghargai diri sendiri sehingga menyebabkan terganggunya perkembangan yang optimal (Edmawati, Hambali \& Hidayah, 2018). Hal ini mengakibatkan kehidupan sehari-harinya tidak berjalan dengan semestinya.

Bentuk-bentuk perilaku yang mengindikasikan Body dysmorphic disorder (Watkins, Thompson, dalam Nourmalita, 2016) adalah sebagai berikut : 1) Secara berkala mengamati bentuk penampilan lebih dari satu jam per hari/ menghindari sesuatu yang dapat memperlihatkan penampilan; 2) Mengukur atau menyentuh kekurangan yang dirasakannya secara berulang-ulang; 3) Meminta pendapat yang dapat memperkuat penampilannya; 4) Menyamarkan kekurangan fisik yang dirasakannya; 5) Menghindari situasi dan hubungan social; 6) Mempunyai sikap obsesi terhadap selebritis atau model yang mempengaruhi penampilan fisiknya; 7)Berpikir untuk melakukan operasi plastic; 8) Selalu tidak puas dengan diagnosis dermatologist atau ahli bedah plastic; 9) Mengubah-ubah gaya dan model rambut untuk menutupi kekurangan yang dirasakannya; 10) Mengubah warna kulit yang diharapkan memberi kepuasan pada penampilan; 11) Berdiet secara ketat dengan kepuasan tanpa akhir.

\section{UPAYA PENGENTASAN GANGGUAN BODY DYSMORPHIC DISORDER}

Tahap awal untuk mengobati pasien dengan BDD yaitu dengan terapi non-farmakologis dengan cara menginterfensi psikologi pasien yang dilakukan oleh psikolog. Terapi yang dikenal dalam menangani pasien tersebut yaitu dengan pendekatan Cognitive-Behavioral Therapy (CBT). Penelitian yang ada menunjukkan bahwa terapi kognitif-perilaku (CBT) mungkin berpengaruh untuk BDD.

Cognitive Behaviour Therapy (CBT) yang dirancang untuk membantu individu memperoleh insight terhadap permasalahannya sehingga individu tersebut dapat mengganti pikiran yang terdistorsi menjadi pemikiran rasional sehingga bisa memunculkan perilaku yang adaptif (Spiegler \& Guevremont, dalam Siregar \& Siregar, 2013).

Spiegler \& Guevremont (dalam Siregar \& Siregar, 2013) menyatakan bahwa CBT merupakan psikoterapi yang berfokus pada ognisi yang dimodifikasi secara langsung, yaitu ketika individu mengubah pikiran maladaptifnya (maladaptive thought) maka secara tidak langsung juga mengubah tingkah lakunya yang tampak (overt action).

Selain itu, penggunaan CBT juga di dukung oleh Yusuf \& Setianto (2013) yang berpendapat bahwa upaya untuk menurunkan stres yang disebabkan oleh faktor psikologis adalah melalui Cognitive Behavior Therapy. Cognitive Behavior Therapy adalah sebuah psikoterapi yang menekankan pentingnya peranan kognitif terhadap apa yang kita rasakan dan lakukan. Cognitive Behavior Therapy / CBT adalah terapi yang memfokuskan pada bagaimana mengubah pemikiran atau keyakinan yang negatif (Beck, 1995).

Kebanyakan studi telah meneliti kombinasi komponen kognitif (misalnya, restrukturisasi kognitif yang berfokus pada perubahan asumsi terkait penampilan dan kepercayaan) dengan komponen perilaku, terutama terdiri dari paparan dan pencegahan respon untuk mengurangi penghindaran terhadap sosial dan perilaku kompulsif. Temuan dari penelitian neuropsikologis (seperti diulas di atas) mendukung penggunaan strategi kognitif-perilaku untuk membantu pasien mengurangi fokusnya pada detail kecil dari penampilan mereka dan justru membantu pasien agar melihat tubuh mereka lebih "holistik".

Terapi CBT akan berkesinambungan dengan terapi farmakologis yang diberikan. Tujuan dari farmakoterapi pada pasien dengan gangguan dismorfik tubuh (BDD) adalah untuk mengurangi gejala dan morbiditas dan mencegah komplikasi. Inhibitor reuptake serotonin (SSRI) berguna dalam pengobatan kondisi ini. Untuk sebagian besar, kelas-kelas lain dari obat, termasuk antidepresan trisiklik (TCA), benzodiazepin, neuroleptik, dan antikonvulsan, yield minimal atau tidak ada perbaikan. Secara umum, penggunaan obat dianjurkan dalam hubungannya dengan intervensi psikososial. Treatment ini dapat dilakukan oleh psikiater (Nurlita \& Lisiswanti, 2016).

Dampak body dysmorphic disorder (BDD) dapat menjadi masalah bagi remaja jika tidak ditangani dengan tepat. Untuk itu perlu adanya intervensi yang bersifat kuratif untuk mengurangi body dysmorphic disorder (BDD) salah satunya melalui konseling kelompok dengan teknik cognitive restructuring. Cognitive restructuring merupakan pendekatan CBT yang bertujuan mengubah pikiran irasional konseli menjadi pikiran yang rasional dan adaptif (Cash et al., dalam Edmawati, Hambali \& Hidayah, 2018). 
Body dysmorphic disorder dilatarbelakangi terjadi proses kognitif maladaptif yang menyebabkan individu memiliki gambaran diri (self-image) negatif. Hal ini memicu individu sulit menerima keadaan diri dengan berfokus pada kekurangan, keterbatasan, kelemahan yang ada pada diri individu tersebut sehingga memicu rendahnya perasaan menerima diri, kesulitan mencintai diri sendiri dan merasa tidak puas dengan keadaan diri. Apabila masalah tersebut tidak diatasi maka dapat menyebabkan terganggunya penyesuaian diri dan penyesuaian sosial individu sehingga menimbulkan frustrasi, berkurangnya kepercayaan diri pada remaja, rendahnya self respect, dan depresi (Edmawati, Hambali \& Hidayah, 2018).

\section{KEPUSTAKAAN}

Edmawati, M. D., Hambali, I. M., \& Hidayah, N. 2018. Keefektifan Konseling Kelompok dengan Teknik Cognitive Restructuring untuk Mereduksi Body Dysmorphic Disorder. Jurnal Pendidikan. 3 (8).

Nourmalita, M. 2016. Pengaruh Citra Tubuh terhadap Gejala Body Dismorphic Disorder yang Dimediasi Harga Diri pada Remaja Putri. Seminar Asean Psychology and Humanity.

Nurlita, D. \& Lisiswanti, R. 2016. Body Dysmorphic Disorder. Jurnal Majority. 5 (5).

Siregar, E. Y., \& Siregar, R. H. 2013. Penerapan Cognitive Behavior Durasi Bermain Games Pada Individu Yang Mengalami Games Addiction Therapy (CBT) Terhadap Pengurangan Jurnal Psikologi. 9 (1).

Yusuf, U., \& Setianto, R. L. 2013. Efektivitas “Cognitive Behavior Therapy” terhadap Penurunan Derajat Stres. Jurnal Mimbar. 29 (2) 